NASA

AVSCOM

Technical Memorandum 105437

Technical Report 91-C-053

AIAA-92-0385

\title{
Calculations of Hot Gas Ingestion for a STOVL Aircraft Model
}

David M. Fricker

Propulsion Directorate

U.S. Army Aviation Systems Command

Lewis Research Center

Cleveland, Ohio

James D. Holdeman

Lewis Research Center

Cleveland, Ohio

and

Surya P. Vanka

University of Illinois

Urbana, Illinois

Prepared for the

30th Aerospace Sciences Meeting and Exhibit

sponsored by the American Institute of Aeronautics and Astronautics

Reno, Nevada, January 6-9, 1992 


\title{
CALCULATIONS OF HOT GAS INGESTION FOR A STOVL AIRCRAFT MODEL
}

\author{
D.M. Fricker ${ }^{*}$ \\ Propulsion Directorate \\ U.S. Army Aviation Systems Command \\ Lewis Research Center \\ Cleveland, Ohio 44135 \\ J.D. Holdeman ${ }^{\dagger}$ \\ National Aeronautics and Space Administration \\ Lewis Research Center \\ Cleveland, Ohio 44135 \\ and \\ S.P. Vanka ${ }^{\ddagger}$ \\ University of Illinois \\ Urbana, Illinois 61801
}

\section{ABSTRACT}

Hot gas ingestion problems for STOVL (Short Take-Off, Vertical Landing) aircraft are typically approached with empirical methods and experience. In this study, the hot gas environment around a STOVL aircraft was modeled as multiple jets in crossflow with inlet suction. The flow field was calculated with a Navier-Stokes, Reynoldsaveraged, turbulent, 3D CFD code using a multigrid technique. A simple model of a STOVL aircraft with four choked jets at $1000 \mathrm{~K}$ was studied at various heights, headwind speeds, and thrust splay angles in a modest parametric study. Scientific visualization of the computed flow field shows a pair of vortices in front of the inlet. This and other qualitative aspects of the flow field agree well with experimental data.

\section{NOMENCLATURE}

$D_{i}=$ characteristic length of jet nozzles, 0.0366 $\mathrm{m}$ (1.44 in)

$\mathrm{H}=$ distance from ground to bottom of the aircraft (aircraft altitude or height)

$U_{\infty}=$ headwind velocity

$V_{i}=$ jet nozzle exit velocity, $633 \mathrm{~m} / \mathrm{s}(2080 \mathrm{ft} / \mathrm{sec})$

$\delta=$ thrust splay angle measured from the downward vertical toward symmetry plane

$\mathrm{k}=$ turbulent kinetic energy

$\varepsilon=$ turbulent energy dissipation

$\mathrm{x}=$ axial Cartesian coordinate, zero at upstream boundary

$x-y=$ vertical plane aligned in axial direction

$\mathrm{x}-\mathrm{z}=$ horizontal plane

$y=$ vertical Cartesian coordinate, zero at ground plane

$y-z=$ vertical plane aligned in spanwise direction $z=$ spanwise Cartesian coordinate, zero at aircraft centerline plane

\section{INTRODUCTION}

Hot gas ingestion can cause significant problems for a STOVL (Short Take-Off, Vertical Landing) aircraft including reduced thrust and compressor stalls. These problems involve many hazards for the pilots including very hard landings. During the design of a STOVL aircraft, hot gas ingestion problems are typically approached with empirical methods and experience ${ }^{1.2}$. Given the power of today's supercomputers and workstations, numerical methods employing efficient algorithms are becoming a viable engineering tool for analysis and design. In a previous endeavor, VanOverbeke \& Holdeman ${ }^{3.4}$ proved the feasibility of CFD analysis for hot gas ingestion. This study is a follow-on effort exploring the practicality of using an efficient numerical method for the problem of hot gas ingestion.

\section{FLOW FIELD DESCRIPTION}

Ingestion of hot gases generates problems in two ways: an average temperature rise results in a loss of engine thrust, and a temperature distortion may cause the engine to stall. Engine exhaust gases may be ingested by far-field and/or near-field mechanisms. A schematic of these mechanisms is shown in Fig. 1.

The far-field mechanism results from the exhaust gases impinging on the ground and forming radial wall jets which flow forward, separate, and mix with the headwind. Near-field ingestion occurs with multiple jet configurations. Wall jets flowing out from the lift jets meet and create an upflow or

Aerospace Engineer, Propulsion Directorate, Member AIAA.

${ }^{\dagger}$ Senior Research Engineer, Internal Fluid Mechanics Division, Member AIAA.

${ }^{\ddagger}$ Associate Professor, Dept. of Mechanical \& Industrial Engineering, Member AIAA. 


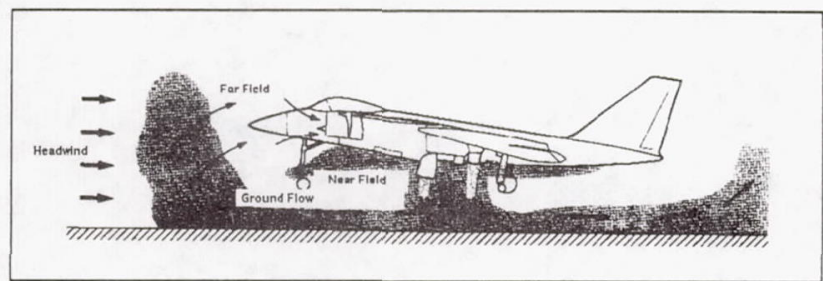

Hot gas ingestion mechanisms
Figure 1

fountain. This fountain flow can impinge on the aircraft's underside, flow along the fuselage to the engine inlets, and be ingested. The gases ingested by this near-field mechanism tend to be hotter, giving greater temperature distortion than those ingested by the far-field mechanism.

As stated earlier, the hot gas environment around a STOVL aircraft was modeled as multiple jets in crossflow with inlet suction. Mass sources represent the nozzle exits, and a mass sink at the end of the inlet provides the suction. The mass injected by the nozzles balances the mass removed by the inlet suction. This configuration derives from the previous study by VanOverbeke \& Holdeman ${ }^{3.4}$. To meet the requirements of the CFD code, the aircraft model is placed in a confined flow, i.e., a 'wind tunnel'. Also, the aircraft model has no angle of attack due to the use of a cartesian grid based flow solver.

The STOVL aircraft model (see Fig. 2) is composed of rectangular solids for the fuselage and engine. For computational simplicity, the nose and

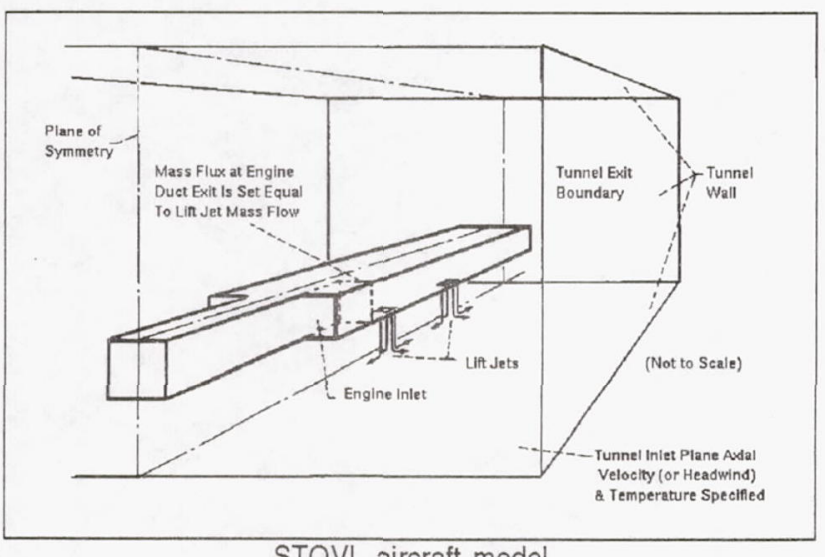

STOVL aircraft model

Figure 2

the tail of the aircraft reach to infinity, and the model lacks wings. Baffles on the sides of the fuselage comprise the walls of the inlet. The nozzles are square in cross-section and are flush with the bottom of the aircraft. The square crosssection of the jets and the rectangular aircraft body result from the use of the cartesian grid.

The four choked nozzles inject air at $1000 \mathrm{~K}$ $\left(1340^{\circ} \mathrm{F}\right)$ straight down into the flowfield with a velocity of $633 \mathrm{~m} / \mathrm{s}(2080 \mathrm{ft} / \mathrm{sec})$. Each lift jet issues from the nozzle exit in a uniform flow. The headwind is also a uniform flow, but at a temperature of $300 \mathrm{~K}\left(81^{\circ} \mathrm{F}\right)$. This approximates an aircraft landing with a forward speed or an aircraft facing into a wind which lacks a boundary layer. In the baseline case, the headwind $\left(U_{\infty}\right)$ flows at $3 \%$ of the jet velocity $\left(\mathrm{V}_{\mathrm{j}}\right)$, or about $19 \mathrm{~m} / \mathrm{s}$ (37 kts), and the distance from the ground to the bottom of the aircraft model $(H)$ is four times the characteristic length of the nozzles $\left(4 D_{j}\right)$. The parametric studies include: various altitudes $\left(H=2\right.$ to $\left.32 D_{i}\right)$ at a constant headwind $\left(U_{\infty}=0.03 V_{j}\right)$; various headwind speeds $\left(U_{\infty}=0.01\right.$ to $\left.0.09 \mathrm{~V}\right)$ for a constant aircraft altitude $\left(H=4 D_{j}\right)$; and various thrust splay angles $\left(\delta=0^{\circ}\right.$ to $\left.45^{\circ}\right)$ for a constant height $\left(H=4 D_{j}\right)$ and headwind speed $\left(\mathrm{U}_{\infty}=0.03 \mathrm{~V}_{\mathrm{j}}\right)$.

The physical dimensions of the aircraft model are given in Table I. Note that the forward and aft nozzles have the same side-to-side separation, i.e., they are in-line, not offset.

Table 1

STOVL aircraft model dimensions

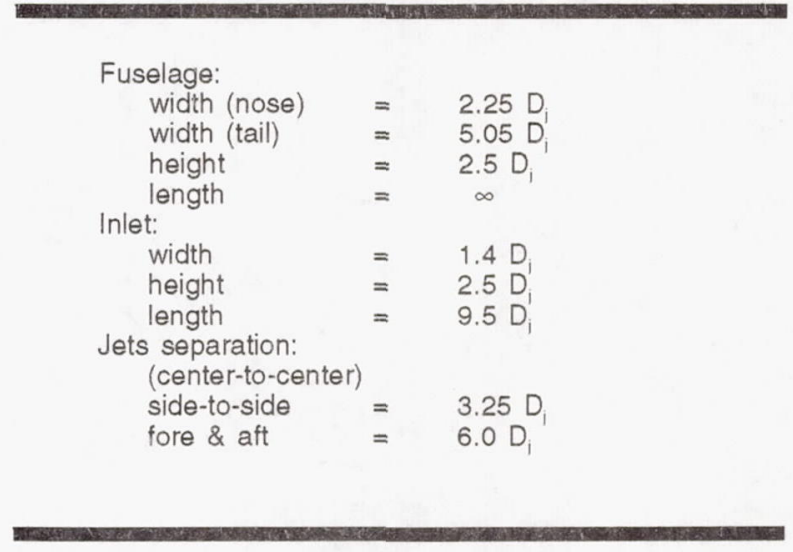

\section{NUMERICAL DESCRIPTION}

\section{Calculation domain}

The grid geometry used for the baseline case is shown in Fig. 3. Exhibited are the centerline plane, the ground plane, and a vertical spanwise plane at the end of the domain as well as the aircraft model. The grid shows the high density of the calculation nodes in the region of the jets. For all calculations, symmetry assumptions allowed calculating only half of the physical domain.

The other boundary conditions for the calculation domain include an inflow simulating the headwind for the domain face in front of the aircraft model and an outflow condition for the domain face behind the model. All flow properties are defined for the inflow condition. The outflow condition, in contrast, merely assumes the properties of the 
axially nearest cells. The top, bottom, and remaining side of the domain are noslip, stationary walls as are the aircraft surfaces. All the walls assume adiabatic conditions for the energy equation. The symmetry plane also has a symmetry condition for the energy equation.

For the height variation, the grid contains 211,200 cells arranged as follows: 100 cells in the $x$ direction, 44 cells in the $y$ direction, and 48 cells in the $z$ direction. The physical dimensions of the baseline grid are about $135 \mathrm{D}_{\mathrm{i}}$ long, $29 D_{i}$ high, and $40 D_{i}$ wide. The aircraft to ground distance was varied by elongating the cells underneath the aircraft. This facilitated the comparative analysis.

The headwind speed variation used a slightly modified grid; 100 cells in $x$, 44 cells in $y$, and 60 cells in $z$ yielding 264,000 total cells. (See Fig. 4.) This grid has a greater length $\left(177 D_{j}\right)$ and greater width $\left(59 D_{j}\right)$ than the baseline grid. Also, the

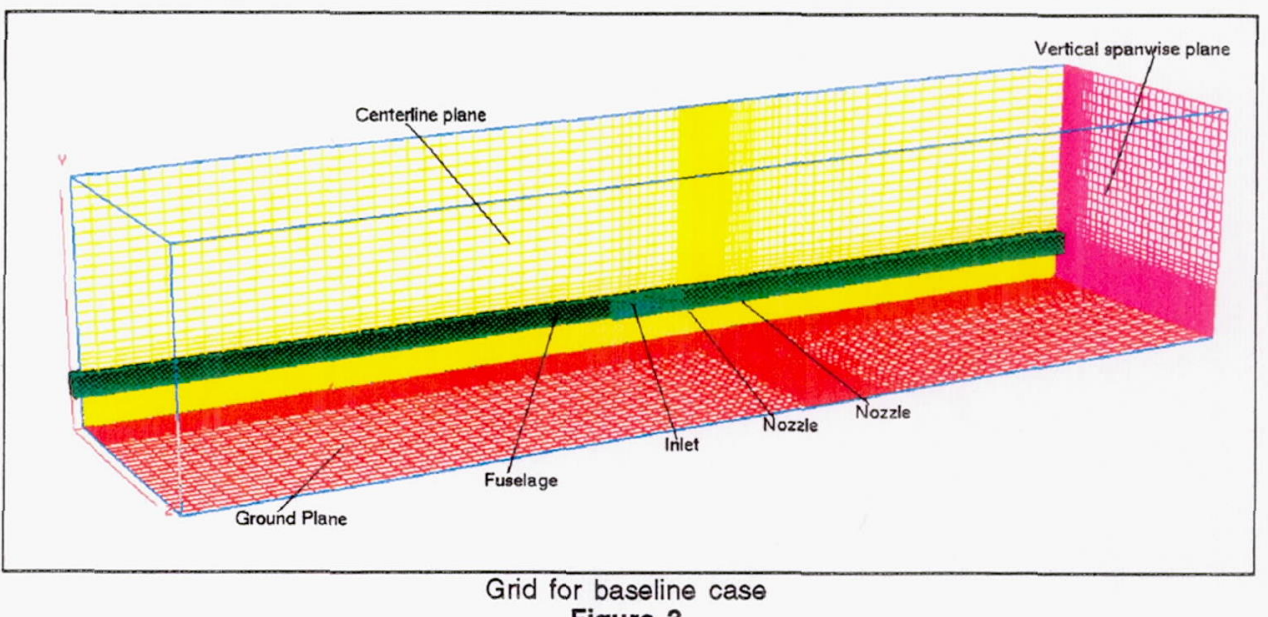
Figure 3 distance in front of the forward pair of jets is greater (152 $D_{j}$ versus $76 \mathrm{D}$ for the baseline grid) to accommodate the long region of hot gas in front of the inlet in the $U_{\infty}=$ $0.01 \mathrm{~V}_{\mathrm{i}}$ case. No grid modification was needed to vary the headwind speed.

\section{Flow solver}

The flow field in this domain was calculated with a Navier-Stokes, Reynolds-averaged CFD code. References 5-7 describe this steady-state CFD code (and its techniques) for the three-dimensional analysis of turbulent elliptic flows in a Cartesian coordinate system.

The CFD code (CART3D) solves the timeaveraged Navier-Stokes or Reynolds equations. The $k-\varepsilon$ turbulence model provides closure. The governing equations include continuity, $x-, y-$, and $z-$ momenta, energy, turbulent kinetic energy, and turbulent energy dissipation. These equations are solved using a block-implicit multigrid algorithm developed by Vanka.

CART3D uses a hybrid differencing scheme on a staggered grid. This means that the code

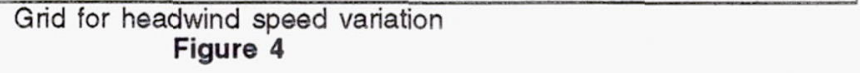

uses central differencing or upwind differencing depending upon the cell's Reynolds number. Also, the scalar properties (density, pressure, etc.) are calculated at the cell volume centers while the velocities are solved at the centers of the cell faces.

The multi-grid technique speeds convergence by solving the equations on sequential grids of different cell densities. The flow is initialized on the coarsest grid which gets refined by the multi-gridding. Dividing each cell on a grid into eight equal cells refines the grid for the next grid level. A V-cycle of sweeps on the various grid levels is performed until the solution converges on the finest grid. This technique speeds convergence by dampening out errors with the various levels of grid refinement.

To determine convergence, the residuals are non-dimensionalized by an appropriate number, and then the maximum of all the residuals is compared to the tolerance criterion. The tolerance criterion used by this study is $1 \%$ for the finest grid. All test cases used the third grid level for the finest grid. 


\section{FLOW FIELD FEATURES}

A short study of the features in the baseline case will help bring out the differences caused by varying the aircraft altitude.

Fig. 5 displays the temperature contours in an $\mathrm{x}$ $z$ plane near the ground. These contours show the locations of the forward vortex pair and the two ground vortices generated by the interaction of the jets and the crossflow. The axis for the forward vortex pair is perpendicular to the plane shown in Fig. 5 while the axes for the ground vortices are parallel to the plane. The forward vortex pair is smeared by the steady-state calculations but still agrees well with the time-averaged experimental data-10.

The particle traces in Fig. 6 reveal ingestion of exhaust gases. The particle traces from the jet region show the forward vortex and ingestion into the inlet. The particle traces starting at the inflow boundary show the headwind's deflection around the forward vortex. Temperature contours along the ground plane are also shown for clarity of position.

Fig. 7 shows a threedimensional temperature contour for the baseline case. This isotherm is for $325 \mathrm{~K}\left(125^{\circ} \mathrm{F}\right)$, a reasonable upper limit on the temperature of the air reaching the engine. With the ambient flow at $300 \mathrm{~K}$ $\left(81^{\circ} \mathrm{F}\right)$, this represents a temperature rise of more than $25 \mathrm{~K}\left(45^{\circ} \mathrm{F}\right)$ for the fluid inside the isotherm. The inlet is almost completely obscured by the contour. Clearly, the engine is exposed to a considerable amount of hot gas from the engine exhaust. The bubble in front of the inlet reveals the location of the forward vortex. Note that the clipping of the isotherm in the right side of Fig.

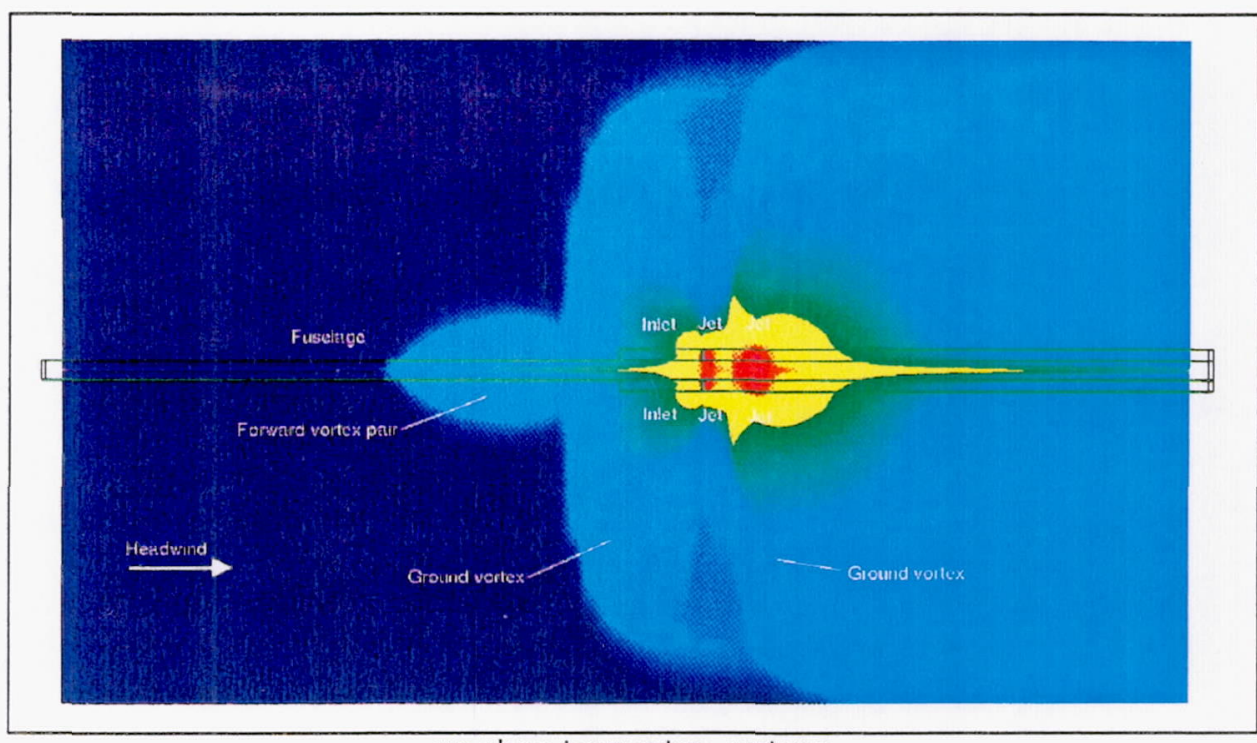

$x-z$ plane temperature contours

$\mathrm{H}=4 \mathrm{D}_{\mathrm{i}}, \mathrm{U}_{\infty}=0.03 \mathrm{~V}_{\mathrm{i}}$

Figure 5
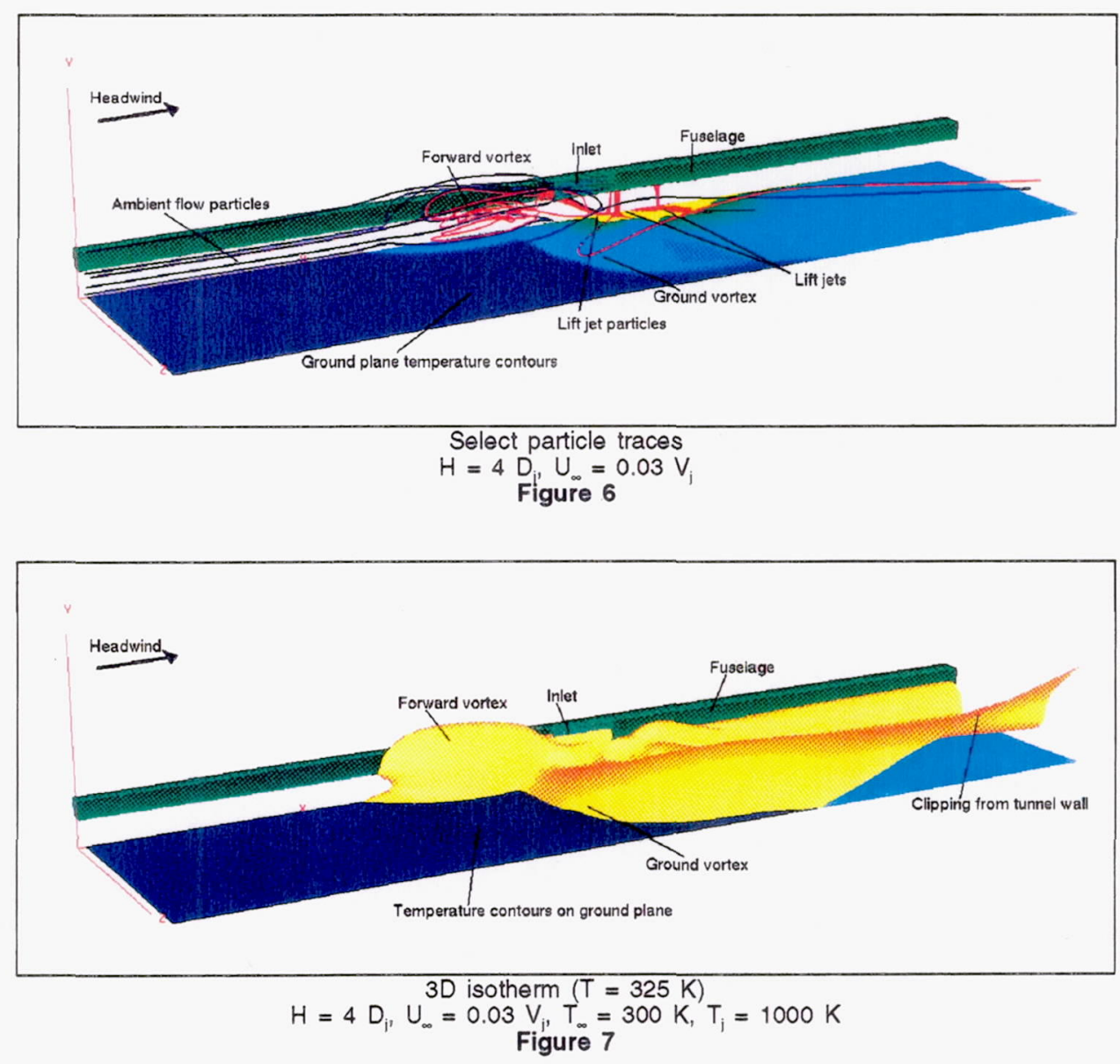

7 is due to wall effects which have no consequence on the hot gas ingestion. 


\section{AIRCRAFT ALTITUDE \\ PARAMETER VARIATION}

The aircraft altitude varied from $2 D_{j}$ to 32 $D_{i}$. The cases actually computed over this range $(H$ $=2,3,4,5,6,8,12,16,24$, and $32 D_{\text {i }}$ ) were carefully chosen to capture the changes in the flow field features. Fig. 8 shows temperature contours for select aircraft altitudes $\left(2 D_{i}, 4 D_{i}, 8 D_{i}, 12 D_{i}\right.$, and $32 D_{j}$ ) in two planes: the ground plane and a vertical plane passing through the jets near the jet centers. These cases show the changes in the flow field affecting hot gas ingestion over the range of variation. In each case, the fuselage is mostly hidden by the vertical plane of temperature contours. The major effects of aircraft altitude can be seen in this figure: the forward vortex changes in character, the amount of hot gas ingested is reduced, and the ground vortices decrease in size.

In Fig. 9, the temperatures at the cells in front of the mass sink or 'engine face' are plotted against the aircraft altitude. The temperatures shown are the minimum, the maximum, and a weighted average based on the cell volumes. The spread of the minimum temperature and the maximum temperature shows the temperature distortion at the engine face. This and the average temperature rise above ambient is plotted in Fig. 10. At low altitudes, the distortion is obviously

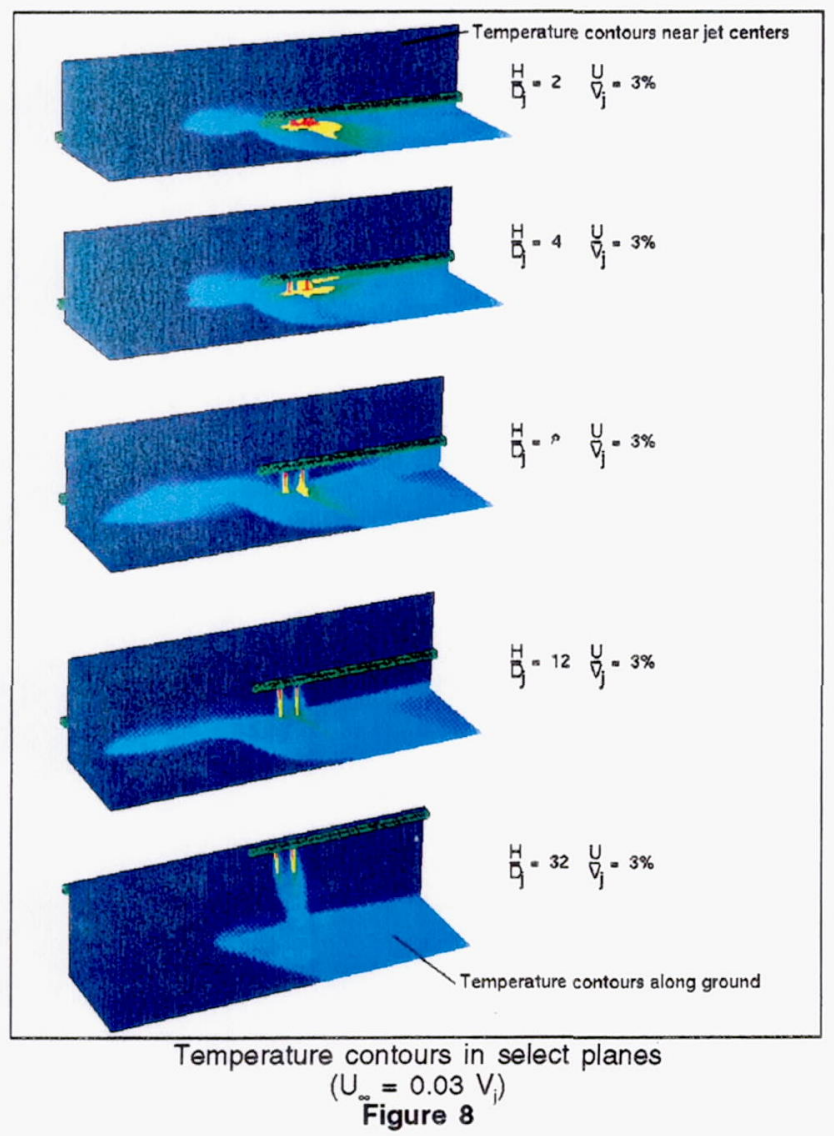

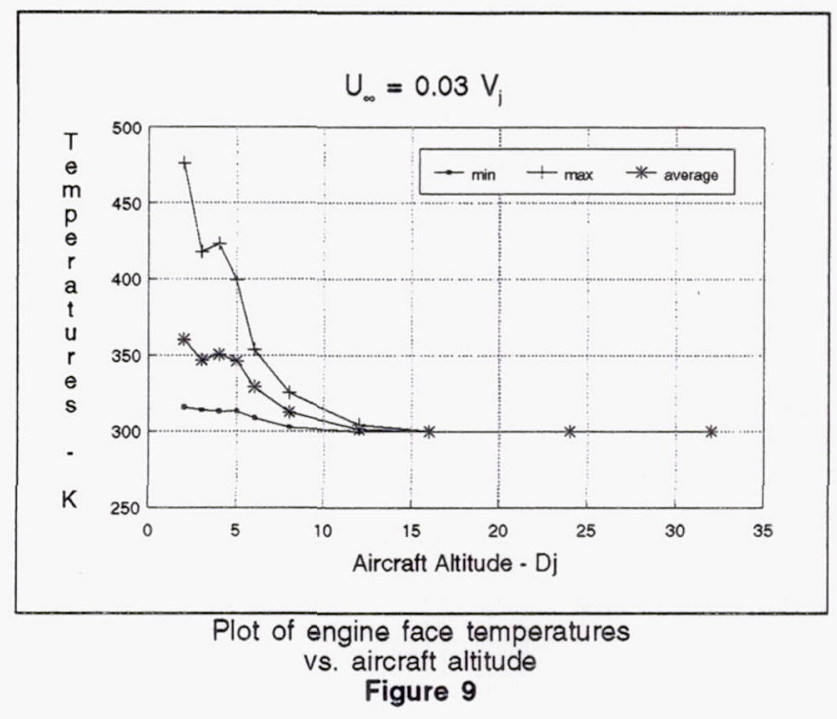

extreme; and it quickly diminishes with increasing altitude. The average temperature shows a similar behavior. The non-monotonic behavior at $\mathrm{H}=3 \mathrm{D}_{\mathrm{i}}$ in all of these curves appears to be physical. Other calculations on different grids exhibit the same trends.

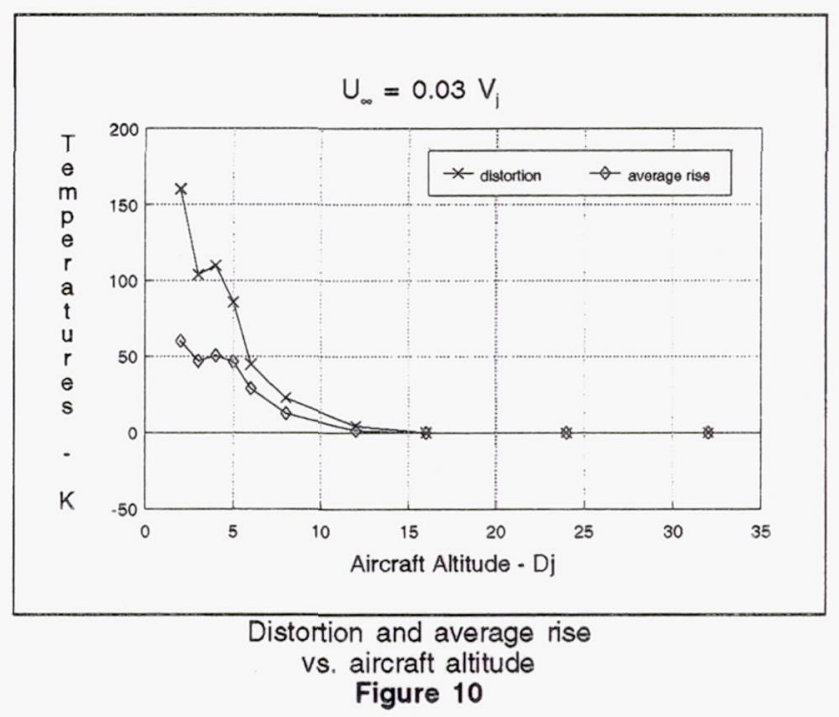

\section{HEADWIND SPEED PARAMETER VARIATION}

The headwind speed was varied from $1 \%$ to $9 \%$ of the jet velocity $\left(U_{\infty}=0.01\right.$ to $\left.0.09 \mathrm{~V}_{\mathrm{j}}\right)$ in $1 \%$ increments for a constant altitude $\left(H=4 D_{j}\right)$. Fig. 11 displays temperature contours in the same two planes as in Fig. 8: the ground plane and a vertical plane passing through the jets near the jet centers. Selected headwind speeds $(1 \%, 3 \%, 5 \%, 7 \%$, and $9 \%$ ) show the changes in the flow field for the varying headwind speed. Again, the fuselage is mostly hidden by the vertical plane of temperature contours. In Fig. 11 the calculated domain includes 


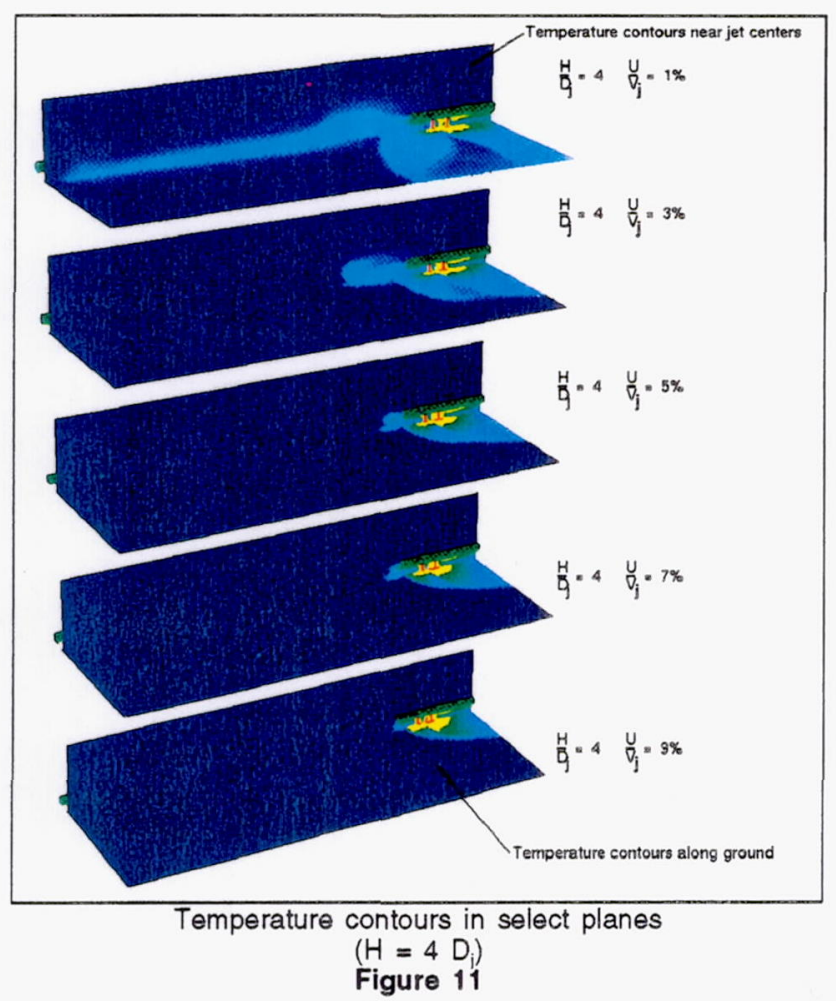

a much larger region in front of the inlet in comparison with Fig. 8. This is due to a very long region of exhaust gas which extends in front of the inlet along the ground in the $U_{\infty}=0.01 \mathrm{~V}_{\text {case }}$.

The effect of headwind speed on the engine face temperatures can be seen in Fig. 12. Note that the minimum temperature declines rather steadily with increasing headwind speed. The temperature distortion at the engine face varies weakly with headwind speed at the low speeds and is greatest for the $7 \%$ case as shown in Fig. 13 . One should note that these high velocity ratios are

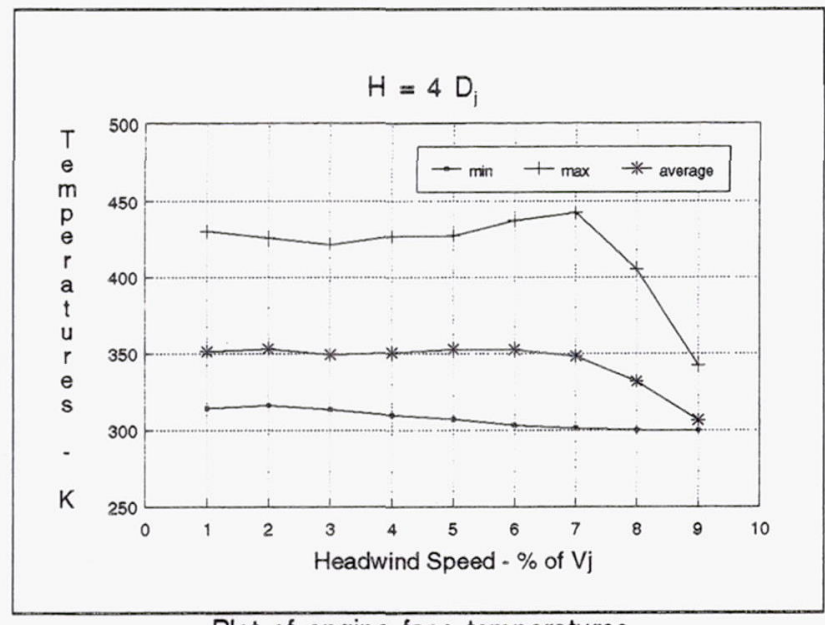

Plot of engine face temperatures

vs. headwind speed

Figure 12 unrealistically representing a windy vertical landing, but they might be relevant for a low speed landing. For choked jets, the $9 \%$ headwind represents about a 110 knot headwind which would either be a hurricane or a slower than normal landing speed for a conventional fighter aircraft.

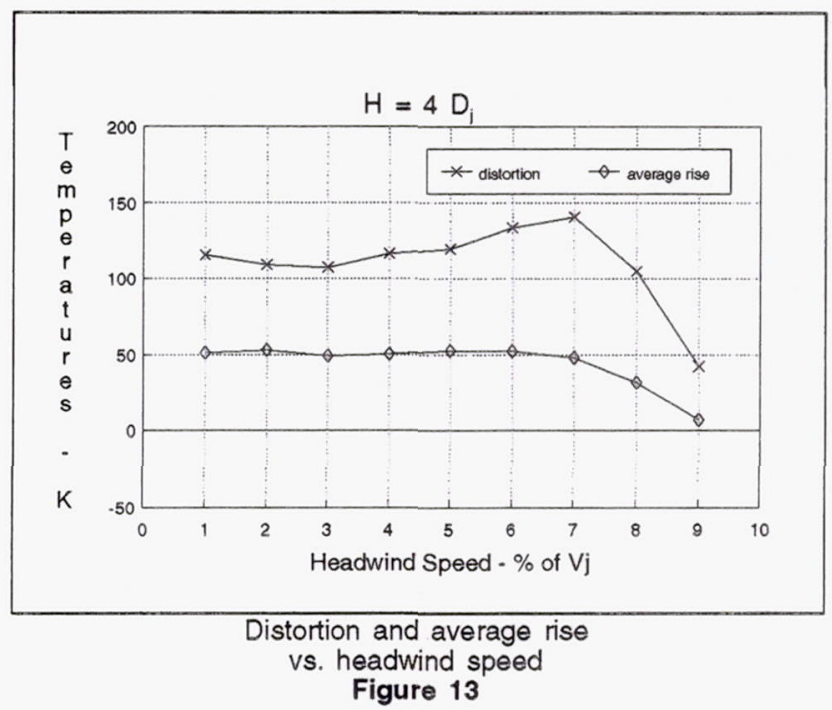

THRUST SPLAY ANGLE PARAMETER VARIATION

A technique used to help control hot gas ingestion is to splay the jets. By angling the lift jets, the relative strengths of the fountain, upwash, and vortices are changed thus changing the flow structures affecting ingestion. In this study, the splay angle $(\delta)$ of the thrust is measured from the downward vertical inward to the centerline plane of the aircraft model. To vary the thrust splay angle, the component velocities on the jets changed to provide the required angle while keeping the speed of the jet constant. Thus the direction of the lift jets changed while the geometry of the aircraft model did not change.

\section{Splaying all jets}

For the first variation of the thrust splay angle, all four jets were splayed the same amount. The splay angle varied from $0^{\circ}$ to $45^{\circ} \cdot\left(\delta=0^{\circ}\right.$ to $\left.45^{\circ}\right)$ in $5^{\circ}$ increments for a constant height $(\mathrm{H}=4$ $\left.D_{j}\right)$ and constant headwind speed $\left(U_{\infty}=0.03 V_{j}\right)$. Fig. 14 shows temperature contours in two planes similar to those displayed in Fig. 8 \& Fig. 11: the ground plane and a vertical plane that is now on the inner side of the lift jets (instead of near the center). Selected splay angles $\left(0^{\circ}, 5^{\circ}, 10^{\circ}, 20^{\circ}\right.$, $25^{\circ}$, and $30^{\circ}$ ) show the changes in the flow structures due to varying the angle of all the jets. The most noticeable change occurs in the length of the hot gas region in front of the inlet. A less noticeable change is the increase of hot gas directly 


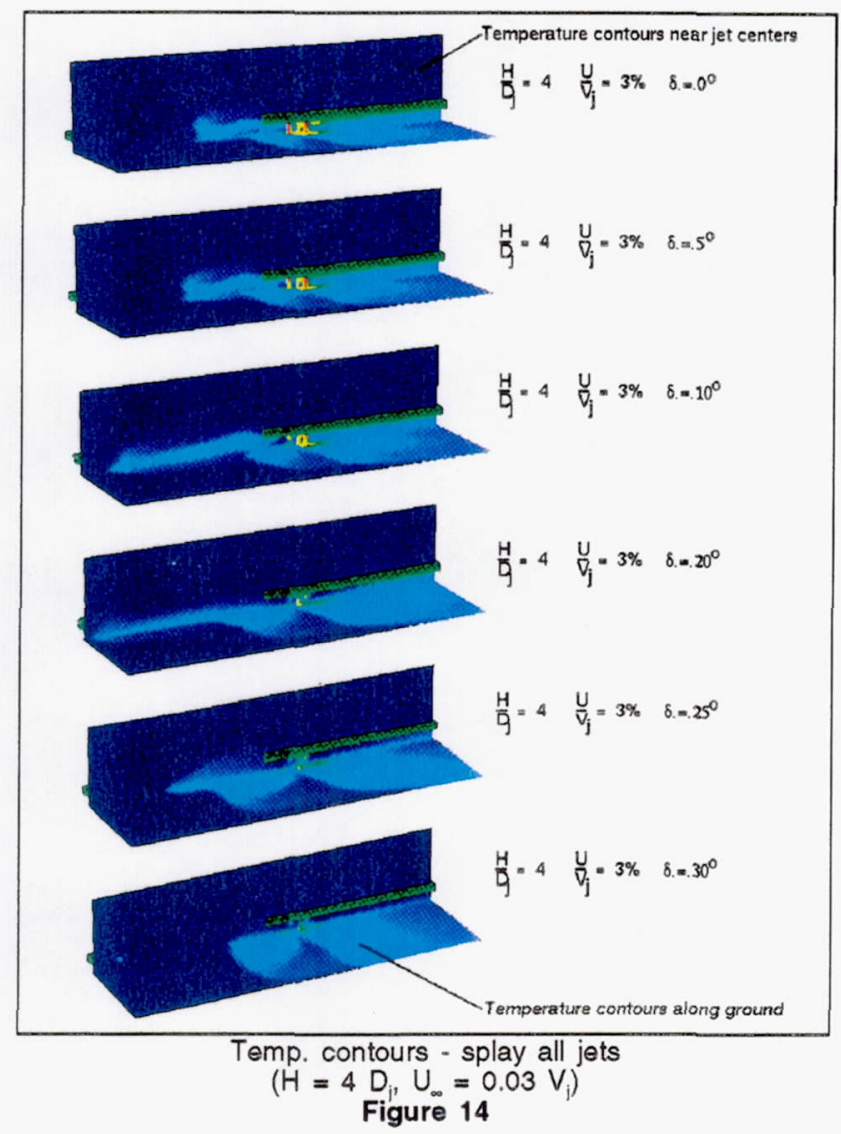

in front of the inlet for the $5^{\circ}$ case. This actually causes an increase in hot gas ingestion over the $0^{\circ}$ case, instead of reducing it.

This and other effects of thrust splay angle for all the jets can be seen in Fig. 15 and Fig. 16 . In Fig. 15, the average temperature first rises and then drops until a splay angle of about $20^{\circ}$ where it starts rising again. A local maximum exists at the $25^{\circ}$ point before the average temperature flattens

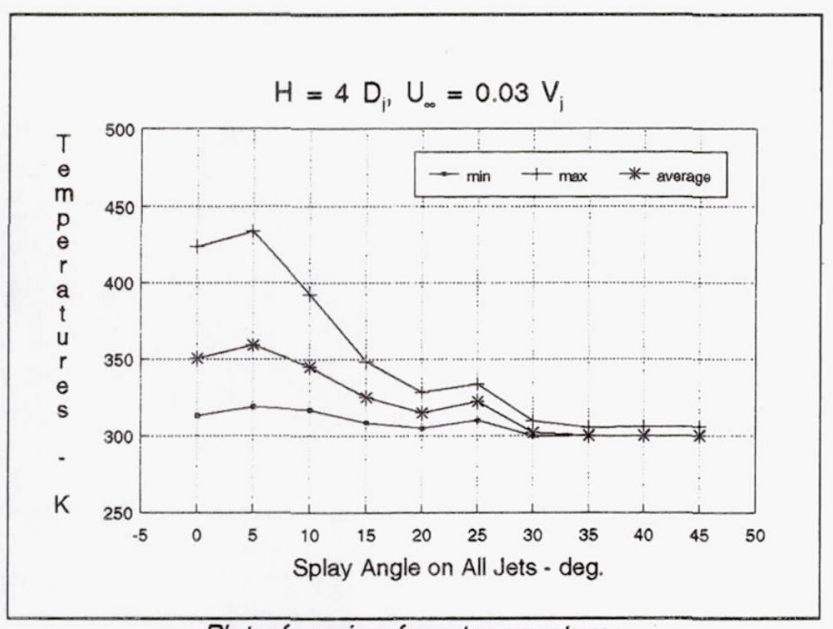

Plot of engine face temperatures

vs. splay angle on all jets

Figure 15 out at its lowest value. Both the minimum and maximum temperatures follow the same behavior. The distortion and average temperature rise displayed in Fig. 16 show the same patterns. Note that for this configuration of model and altitude, the jets will converge at the ground for a thrust splay angle of $22^{\circ}$.

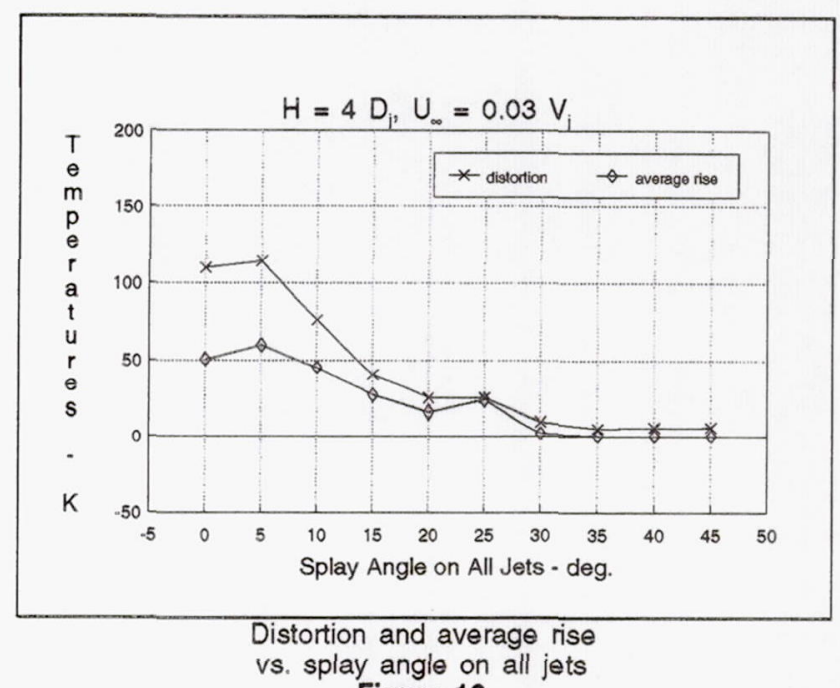

Figure 16

\section{Splaying forward jets only}

In the second variation, only the forward jets varied in thrust splay angle. The rear lift jets maintained a $0^{\circ}$ splay angle. Again, the thrust splay angle varied from $0^{\circ}$ to $45^{\circ}\left(\delta=0^{\circ}\right.$ to $\left.45^{\circ}\right)$ in $5^{\circ}$ increments at the same altitude $\left(H=4 D_{j}\right)$ and headwind speed $\left(U_{\infty}=0.03 V_{j}\right)$ just as in the all jets splayed variation. Fig. 17 shows the temperature contours in the same two planes as in Fig. 14: the ground plane and a vertical plane on the inner side of the lift jets. Again, the selected splay angles $\left(0^{\circ}\right.$, $5^{\circ}, 10^{\circ}, 20^{\circ}, 25^{\circ}$, and $30^{\circ}$ ) show the changes in the flow structures due to varying the angle of the forward jets alone. The flow field changes are basically the same as in the cases with all the jets splayed.

The ingestion effects of thrust splay angle for the forward jets can be seen in Fig. 18. The average temperature first rises and then drops until a splay angle of about $20^{\circ}$ where it rises very slightly. A local maximum exists at $25^{\circ}$ splay angle before the average temperature drops and flattens out at its lowest value. Both the minimum and maximum temperatures follow a similar behavior. The distortion and average temperature rise displayed in Fig. 19 show the same patterns, just as when all the jets are splayed. Overall, splaying the forward jets alone gives the same effects on hot gas ingestion as splaying all the jets. 


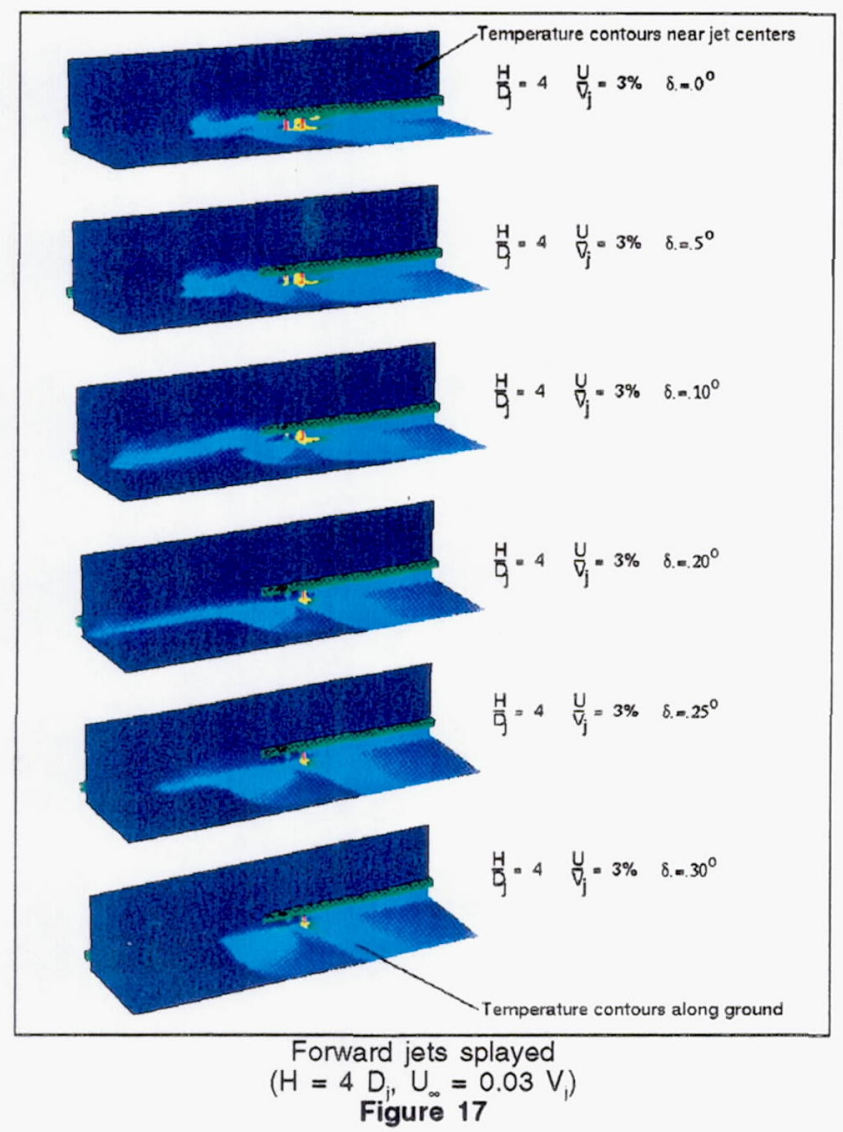

\section{CONCLUSIONS/REMARKS}

In summary, the average of the engine face temperatures decreases with increasing height but is relatively unaffected by headwind speed. Engine face temperature distortion also decreases with increasing height, but unexpectedly increases with headwind speed until the forward vortex is behind the inlet face. The headwind speed variation reveals that (for a constant height) the engine face temperature is dominated by near field ingestion effects.

As for the thrust splay angle variation, splaying the jets inward (for a constant height and headwind speed) first causes a rise and then a rapid decrease in hot gas ingestion, although a local maximum exists when the jets converge at the ground plane. Also, splaying the forward jets alone instead of all the jets gives almost the same reduction in hot gas ingestion without as large a thrust penalty.

A comparison of the $\mathrm{H}=4 \mathrm{D}_{\mathrm{j}}, \mathrm{U}=0.03 \mathrm{~V}$ cases in the height parameter variation and the headwind speed parameter variation show the effects of the calculation domain on the flow field. The vertical walls of the narrower calculation domain definitely affect the ground vortices, but no differences exist in the temperatures reaching the

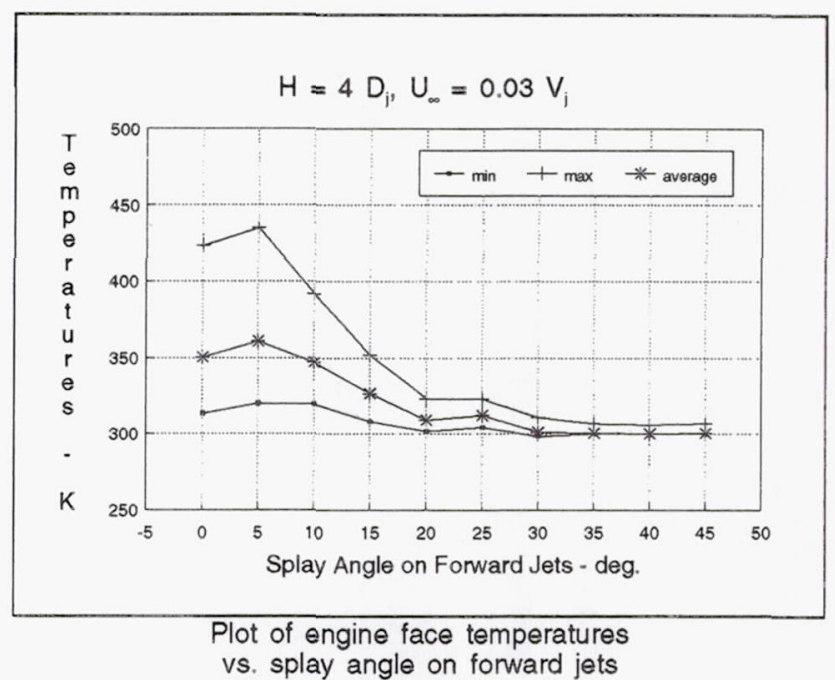

Figure 18

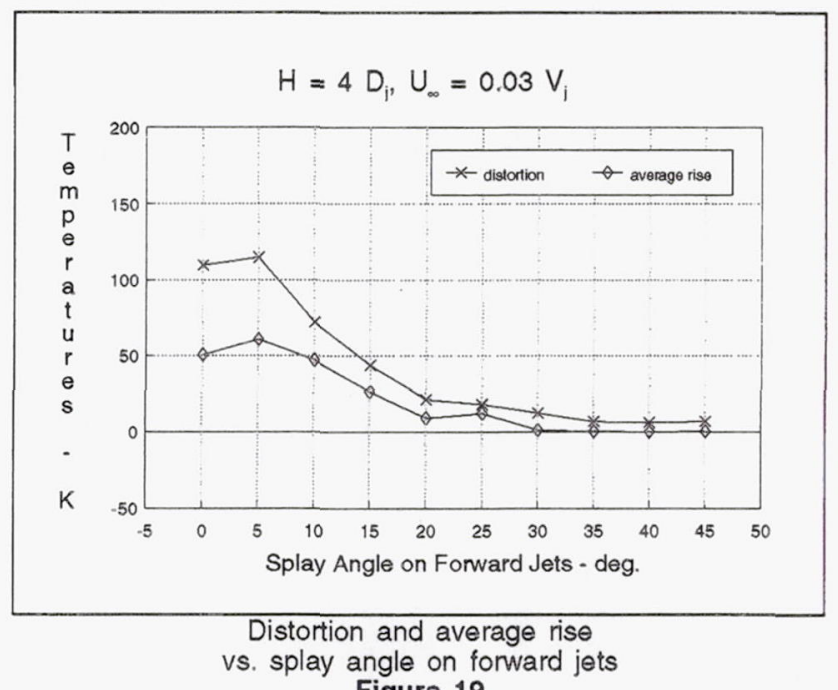

Figure 19

engine. Essentially, the tunnel walls in the calculation domain used for the height parameter variation are sufficiently far from the aircraft model so as to not affect the desired quantities (engine face temperatures). If the overall flow field is of primary interest, then the tunnel walls would have to be farther from the aircraft model.

This study did not address the importance of the aircraft geometry (fuselage, wings, tails, etc.) in relation to the flow field. Only one aircraft model was used, and it was quite simplistic.

The last conclusion from this study concerns the practicality of using an efficient CFD code for parameter variation studies. The turn-around time on a Cray-2 supercomputer and state-of-the-art workstations allows quick parameter changes. Typically, a Cray-2 supercomputer solved the flow field in about an hour with a turn-around time of a day. A dedicated IBM RS-6000 workstation can 
solve the flow field in about 6 hours and can actually give shorter turn-around than the shared supercomputer.

\section{REFERENCES}

1. Kuhn, R.E., "Design Concepts for Minimizing Hot-Gas Ingestion in V/STOL Aircraft," Journal of Aircraft, Vol. 19, No. 10, Oct. 1982, pp. 845-850.

2. Kuhn, R.E., and Eshelman, J., "Ground Effects on V/STOL and STOL Aircraft--A Survey," AIAA Paper 85-4033, Oct. 1985. (NASA TM-86825).

3. VanOverbeke, T.J., and Holdeman, J.D., "A Numerical Study of the Hot Gas Environment Around a STOVL Aircraft in Ground Proximity," AIAA Paper 88-2882, July 1988. (NASA TM 100895).

4. VanOverbeke, T.J., and Holdeman, J.D., "Three-Dimensional Turbulent Flow Code Calculations of Hot Gas Ingestion," Journal of Aircraft, Vol. 27, No. 7, July 1990, pp 577-582.

5. Vanka, S.P., "Block-implicit Multigrid Solution of Navier-Stokes Equations in Primitive Variables," Journal of Computational Physics, Vol. 65 , July 1986, pp. 138-158.

6. Vanka, S.P., "Efficient Computation of Viscous Internal Flows, SBIR Phase I Report (NAS3-25573)," August 1989.

7. Tafti, D., and Vanka, S.P., "Hot Gas Environment Around STOVL Aircraft in Ground Proximity, Part II: Numerical Study," AIAA Paper 902270, July 1990.

8. McLean, R., Sullivan, J., and Murthy, S.N.B., "Hot Gas Environment Around STOVL Aircraft in Ground Proximity--Part I: Experimental Study," AIAA Paper 90-2269, July 1990.

9. McLean, R.J, "The Flowfield Around a STOVL Aircraft Model in Ground Effect," May 1991, NASA CR187091.

10 . Johns, A.L., Neiner, G., and Bencic, T.J., "Hot Gas Ingestion Test Results of a TwoPoster Vectored Thrust Concept With Flow Visualization in the NASA Lewis 9- by 15-Foot Low Speed Wind Tunnel," AIAA Paper 90-2268. (NASA TM 103258). 
Public reporting burden for this collection of information is estimated to average 1 hour per response, including the time for reviewing instructions, searching existing data sources, gathering and maintaining the data needed, and completing and reviewing the collection of information. Send comments regarding this burden estimate or any other aspect of this collection of information, including suggestions for reducing this burden, to Washington Headquarters Services, Directorate for information Operations and Reports, 1215 Jefferson Davis Highway, Suite 1204, Arlington, VA 22202-4302, and to the Office of Management and Budget, Paperwork Reduction Project (0704-0188), Washington, DC 20503.

\begin{tabular}{|l|c|c|}
\hline 1. AGENCY USE ONLY (Leave blank) & $\begin{array}{r}\text { 2. REPORT DATE } \\
1992\end{array}$ & $\begin{array}{r}\text { 3. REPORT TYPE AND DATES COVERED } \\
\text { Technical Memorandum }\end{array}$ \\
\hline
\end{tabular}

4. TITLE AND SUBTITLE

Calculations of Hot Gas Ingestion for a STOVL Aircraft Model

6. $\operatorname{AUTHOR}(\mathrm{S})$

David M. Fricker, James D. Holdeman, and Surya P. Vanka
5. FUNDING NUMBERS

WU-505-68-71
7. PERFORMING ORGANIZATION NAME(S) AND ADDRESS(ES)

NASA Lewis Research Center

Cleveland, Ohio 44135-3191

and

Propulsion Directorate

U.S. Army Aviation Systems Command

Cleveland, Ohio 44135-3191

9. SPONSORING/MONITORING AGENCY NAMES(S) AND ADDRESS(ES)

National Aeronautics and Space Administration

Washington, D.C. 20546-0001

and

U.S. Army Aviation Systems Command

St. Louis, Mo. 63120-1798
8. PERFORMING ORGANIZATION REPORT NUMBER

E-6808

10. SPONSORING/MONITORING AGENCY REPORT NUMBER

NASA TM-105437

AIAA - $92-0385$

AVSCOM TR-91-C-053

11. SUPPLEMENTARY NOTES

Prepared for the 30th Aerospace Sciences Meeting and Exhibit sponsored by the American Institute of Aeronautics and Astronautics, Reno, Nevada, January 6-9, 1992. David M. Fricker, Propulsion Directorate U.S. Army Aviation Systems Command, James D. Holdeman, NASA Lewis Research Center, and Surya P. Vanka, University of Illinois, Urbana, Illinois 61801. Responsible person, David M. Fricker, (216) 433-5960.

12a. DISTRIBUTION/AVAILABILITY STATEMENT

12b. DISTRIBUTION CODE

Unclassified - Unlimited

Subject Category 02

13. ABSTRACT (Maximum 200 words)

Hot gas ingestion problems for STOVL (Short Take-Off, Vertical Landing) aircraft are typically approached with empirical methods and experience. In this study, the hot gas environment around a STOVL aircraft was modeled as multiple jets in crossflow with inlet suction. The flow field was calculated with a Navier-Stokes, Reynolds-averaged, turbulent, 3D CFD code using a multigrid technique. A simple model of a STOVL aircraft with four choked jets at $1000 \mathrm{~K}$ was studied at various heights, headwind speeds, and thrust splay angles in a modest parametric study. Scientific visualization of the computed flow field shows a pair of vortices in front of the inlet. This and other qualitative aspects of the flow field agree well with experimental data.

\section{SUBJECT TERMS}

STOVL; Hot gas ingestion; Computational fluid dynamics; Modeling; Elliptic flow

15. NUMBER OF PAGES

13

16. PRICE CODE

17. SECURITY CLASSIFICATION OF REPORT

Unclassified

18. SECURITY CLASSIFICATION
OF THIS PAGE
Unclassified

19. SECURITY CLASSIFICATION OF ABSTRACT

Unclassified

$\mathrm{A03}$

$\mathrm{A} 03$

20. LIMITATION OF ABSTRACT 